\title{
Renal Denervation in Daily Practice: If So, How?
}

\author{
Dominic Millenaar $^{1} \cdot$ Insa Emrich $^{1} \cdot$ Felix Mahfoud $^{1}{ }^{[}$
}

Received: 3 April 2020 / Accepted: 11 April 2020 / Published online: 23 April 2020

(C) The Author(s) 2020

It is estimated that $30-45 \%$ of all adults have hypertension with an increasing prevalence with advancing age [1]. Antihypertensive drugs are essential and effective components of hypertension management but often limited by non-adherence [2]. Catheter-based renal denervation (RDN) represents a device-based hypertension treatment option, which lowers blood pressure by targeting renal sympathetic nerve activity $[3,4]$. RDN has proven both, its safety and efficacy in recently published, sham-controlled studies [5-7]. These studies included mild-moderate hypertensive individuals not treated with antihypertensive medication (SPYRAL Hypertension-Off Medication [6], RADIANCE-HTN SOLO-A study of the ReCor Medical Paradise System in Clinical Hypertension [5]) and patients on 1-3 commonly prescribed antihypertensive drugs (SPYRAL Hypertension-On Medication [7]). In order to put these results into perspective one has to keep in mind that the patients enrolled in these trials were distinctly different from those investigated in previous studies [3, 4], which mainly included severe, resistant hypertensive patients on multiple medications. Hence, the 2013 European Society of Cardiology (ESC)/European Society of Hypertension (ESH) Guidelines for the management of hypertension recommended that RDN may be considered in patients with uncontrolled resistant hypertension on 3 or more different antihypertensive drug classes, one of which had to be a diuretic (class of recommendations IIb, level of evidence C) [8]. This recommendation was revised in the current 2018 ESC/ESH Guidelines [9], where the use of device-based therapies (including RDN) for the routine treatment of hypertension outside clinical studies is not recommended, given that the evidence available at the time of writing of the guidelines was considered not informative enough. However, the 2018 ESC/ESH guidelines called for

Dominic Millenaar

Dominic.Millenaar@uks.eu

1 Klinik für Innere Medizin III, Kardiologie, Angiologie und Internistische Intensivmedizin, Universitätsklinikum des Saarlandes, Kirrberger Str. 1, IMED, Building 41, 66421 Homburg/Saar, Germany further placebo-controlled trials of device-based therapies. In light of the results of the recently published sham-controlled studies, including the first positive pivotal study, societies may wish to update their recommendations. Against this background, the present position paper by the Italian Society of Arterial Hypertension aims to clarify some of the issues related to patient and center selection for RDN [10].

The manuscript focuses on the importance of adherence and persistence as a key component of successful blood pressure control but also discusses the high prevalence of non-adherence among patients with uncontrolled/difficult to control hypertension [10]. The authors discuss the current evidence on efficacy and safety of RDN. The first trials-SYMPLICITY Hypertension-1 [3] and Hypertension-2 [4] - indicated reasonable safety and efficacy of RDN in resistant hypertension. However, SYMPLICITY Hypertension-3 [11] as the first sham-controlled trial failed to meet the primary efficacy endpoint. The potential reasons for the failure of SYMPLICITY Hypertension-3 [11] - as discussed in the paper-were, among others, (1) inappropriate patient selection, with inclusion of patients with isolated systolic hypertension possibly due to advanced end organ damage, (2) inconsistent and varying antihypertensive therapy throughout follow-up, (3) lack of adherence measurements and (4) incomplete RDN procedures. This study is now contrasted by 3 independently designed randomized, sham-controlled studies [5-7]. At the 2020's annual meeting of the American College of Cardiology the first pivotal study on RDN was presented and simultaneously published [12]. The trial included 331 patients with a 1:1 randomization to either radiofrequency RDN or a sham procedure. Patients had office systolic blood pressure (SBP) between 150-180 $\mathrm{mmHg}$ and office diastolic blood pressure (DBP) of at least $90 \mathrm{mmHg}$ and a mean 24-h SBP in the ambulatory blood pressure monitoring (ABPM) of $140-170 \mathrm{mmHg}$, respectively. The primary endpoint was baseline-adjusted change in 24-h SBP and the secondary, powered endpoint was baseline-adjusted change in office SBP from baseline to 3 months. Both efficacy endpoints were met with a treatment difference in SBP according to ABPM of $-3.9 \mathrm{mmHg}$ 
(Bayesian 95\% credible interval -6.2 to -1.6 ) and a difference of $-6.5 \mathrm{mmHg}(-9.6$ to -3.5$)$ in SBP according to office blood pressure measurements.

The expert group of the Italian Society of Hypertension provided clear recommendations for patient selection and minimum requirements for RDN centers in a coherent flow chart. They endorse offering RDN primarily to patients with resistant hypertension, despite treatment with reninangiotensin-system (RAS)-blockers, diuretics and calciumchannel-blockers (CCB) at maximally tolerated doses. Also, patients with intolerance to one or more of these drugs or patients with poor adherence may be considered for RDN. RDN procedures should be performed in highly specialized hypertension centers, with expertise in hypertension care and sufficient experience with renal artery interventions (i.e. certified operators, volume of renal procedures $>20$ /year and the equipment to assess ABPM and to screen for causes of secondary hypertension).

The flowchart highlights five central approaches to optimize blood pressure-lowering treatment to achieve control, before continuing further evaluation for RDN. One of these steps is "screening for secondary hypertension". Of note, the prevalence of secondary hypertension among patients with uncontrolled hypertension is estimated to be $5-10 \%$ [13]. As of today, causes for secondary hypertension have not been systematically excluded in patients prior enrollment in RDN trials and registries. Yet, patients with a known secondary hypertension, i.e. primary aldosteronism or Cushing's syndrome, were excluded, thus data on the efficacy of RDN in secondary hypertension are lacking. However, one may argue that patients with sleep apnea or moderate renal artery stenoses may not generally be disqualified for RDN treatment. Future studies are needed to particularly investigate this patient cohort at high cardiovascular risk. Whether a standardized screening algorithm for all causes of secondary hypertension is feasible and useful in clinical practice remains to be shown.

Another approach highlighted by the authors is "shared decision making". Shared decision making has become an increasingly recognized component of societal guidelines [9]. Physicians and health care providers should comprehensively discuss the present condition, followed by an exchange of knowledge made relevant and understandable to the patient with the help of a structured dialog. Shared decision making is vital in the management of several cardiovascular diseases, e.g. aortic valve disease in elderly patients or left-main coronary heart disease with low to moderate SYNTAX-Score. In the 2019 ESC Guidelines for the diagnosis and management of chronic coronary syndromes, for instance, it is recommended to include patient's preference not only for selection of potential diagnostic steps in situations with low pre-test probability, but also for choosing the optimal treatment option. Whether shared decision making improves hard outcomes in chronically ill patients though, is incompletely understood [14]. Shared decision making in daily clinical practice however, can be challenging. Patients with difficult to control hypertension, who consult Hypertension Excellence Centers have generally be seen for years by several specialists and have likely be treated with various antihypertensive drugs in different doses and combinations. For these patients, device-based hypertension treatment, and in particular RDN, may represent an alternative and potentially attractive option. Interestingly, a recent survey conducted in Germany revealed that $38.2 \%$ of hypertensive patients not yet taking antihypertensive medication would prefer RDN over life-long medical therapy [15]. The likelihood of preference for RDN was higher in younger patients and in men. Eligible patients should be informed about the efficacy and safety profile of the technique but also about the fact that RDN will likely not replace antihypertensive medication in many patients but may reduce blood pressure throughout the 24-h cycle [12].

Further, the Italian Society of Hypertension also suggested performing "drug adherence and tolerability assessments". Drug adherence assessments using toxicological analyses have gained significant interest in the scientific community but are rather expensive, not widely available, laborious measurement with the limitation that dosage changes cannot adequately be detected. Moreover, measurement of drug adherence remains often without direct therapeutic implications other than patient counselling and simplifying antihypertensive drug regimen, all of which should be part of contemporary hypertension management anyway. However, one may argue that knowledge about drug adherence can provide valuable information about patients' willingness to adhere to antihypertensive drugs, which may facilitate shared decision making.

In summary, the Italian Society of Hypertension provided a clinically useful and up to date position paper on the role of RDN for the management of the difficult-to-treat hypertensive patients. The flowchart is helpful for the selection of diagnostic and therapeutic approaches. One of the welcome shifts under way in medicine is the move towards shared decision making, in particular in cardiovascular medicine. As patients in clinical practice may differ from those enrolled in the most recent RDN trials, we propose a slightly revised step-by-step evaluation algorithm depicted in Fig. 1 highlighting shared decision making. The future of medicine lies in sharing medicine, not only within our community of learning and practice but more importantly with our patients. 
Fig. 1 Revised flowchart for patient selection suitable for RDN, focusing on shared decision making. $A B P M$ ambulatory blood pressure monitoring, $B P$ blood pressure, $C V$ cardiovascular, $G P$ general physician, $R D N$ renal denervation

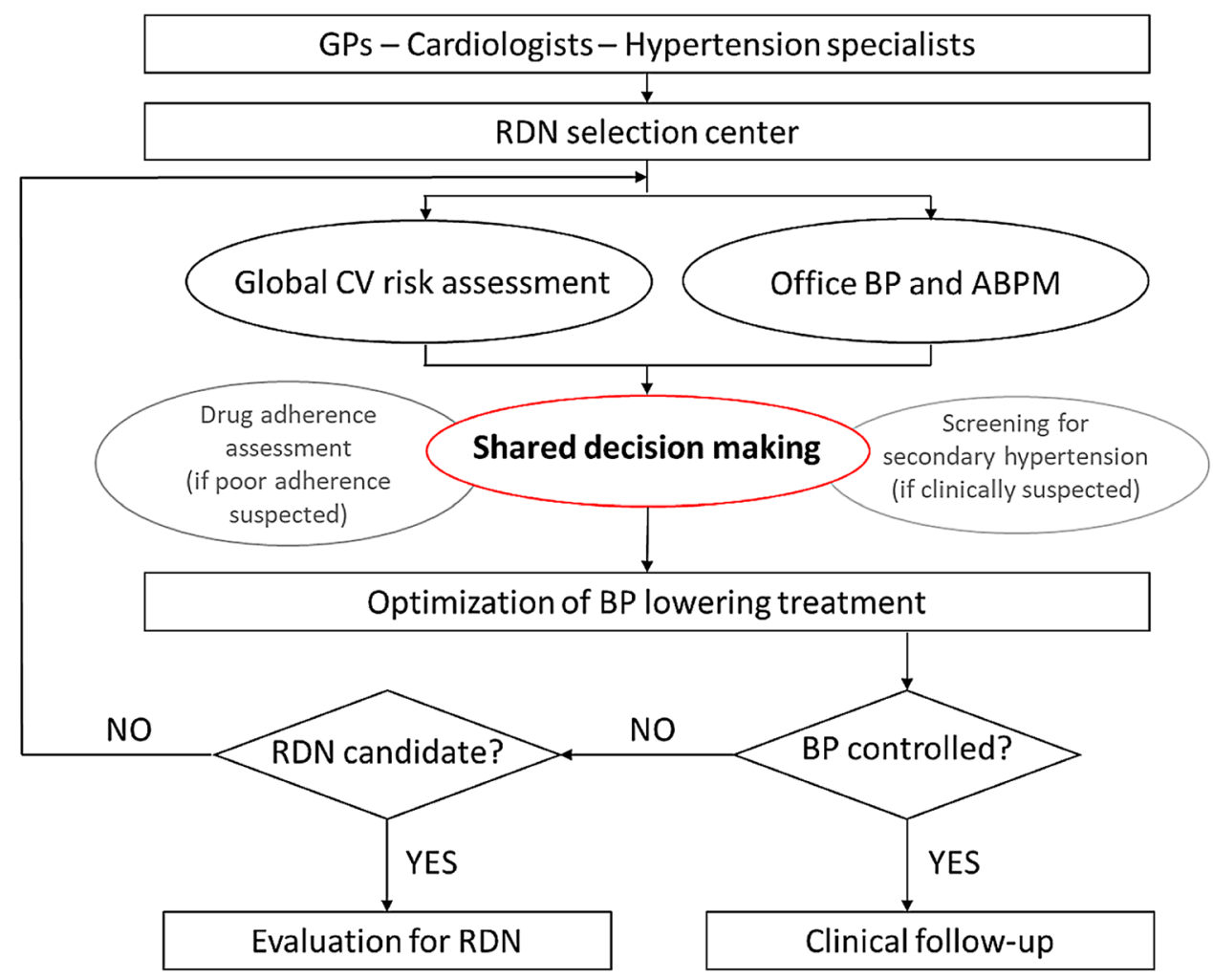

Acknowledgements Open Access funding provided by Projekt DEAL. FM is supported by Deutsche Gesellschaft für Kardiologie (DGK), and Deutsche Forschungsgemeinschaft (SFB TRR219) and has received scientific support and speaker honoraria from Bayer, Boehringer Ingelheim, Medtronic and ReCor Medical. The remaining authors have no disclosures to report.

Open Access This article is licensed under a Creative Commons Attribution-NonCommercial 4.0 International License, which permits any non-commercial use, sharing, adaptation, distribution and reproduction in any medium or format, as long as you give appropriate credit to the original author(s) and the source, provide a link to the Creative Commons licence, and indicate if changes were made. The images or other third party material in this article are included in the article's Creative Commons licence, unless indicated otherwise in a credit line to the material. If material is not included in the article's Creative Commons licence and your intended use is not permitted by statutory regulation or exceeds the permitted use, you will need to obtain permission directly from the copyright holder.To view a copy of this licence, visit http://creativecommons.org/licenses/by-nc/4.0/.

\section{References}

1. Forouzanfar MH, Liu P, Roth GA, et al. Global burden of hypertension and systolic blood pressure of at least 110 to $115 \mathrm{~mm} \mathrm{Hg}$, 1990-2015. JAMA. 2017;317:165-82.

2. Judd E, Calhoun DA. Apparent and true resistant hypertension: definition, prevalence and outcomes. J Hum Hypertens. 2014;28:463-8.

3. Krum H, Schlaich MP, Sobotka PA, Böhm M, Mahfoud F, RochaSingh K, Katholi R, Esler MD. Percutaneous renal denervation in patients with treatment-resistant hypertension: final 3-year report of the symplicity HTN-1 study. Lancet (London, England). 2014;383:622-9.

4. Esler MD, Krum H, Sobotka PA, Schlaich MP, Schmieder RE, Böhm M. Renal sympathetic denervation in patients with treatment-resistant hypertension (The Symplicity HTN-2 Trial): a randomised controlled trial. Lancet (London, England). 2010;376:1903-9.

5. Azizi M, Schmieder RE, Mahfoud F, et al. Endovascular ultrasound renal denervation to treat hypertension (RADIANCEHTN SOLO): a multicentre, international, single-blind, randomised, sham-controlled trial. Lancet (London, England). 2018;391:2335-45.

6. Townsend RR, Mahfoud F, Kandzari DE, et al. Catheter-based renal denervation in patients with uncontrolled hypertension in the absence of antihypertensive medications (SPYRAL HTN-OFF MED): a randomised, sham-controlled, proof-of-concept trial. Lancet (London, England). 2017;390:2160-70.

7. Kandzari DE, Böhm M, Mahfoud F, et al. Effect of renal denervation on blood pressure in the presence of antihypertensive drugs: 6-month efficacy and safety results from the SPYRAL HTN-ON MED proof-of-concept randomised trial. Lancet (London, England). 2018;391:2346-55.

8. Mancia G, Fagard R, Narkiewicz K, et al. 2013 ESH/ESC guidelines for the management of arterial hypertension: the Task Force for the Management of Arterial Hypertension of the European Society of Hypertension (ESH) and of the European Society of Cardiology (ESC). Eur Heart J. 2013;34:2159-219.

9. Williams B, Mancia G, Spiering W, et al. 2018 ESC/ESH Guidelines for the management of arterial hypertension. Eur Heart $\mathrm{J}$. 2018;39:3021-104.

10. Bruno RM, Taddei S, Borghi C, et al. Italian Society of Arterial Hypertension (SIIA) Position Paper on the Role of Renal Denervation in the Management of the Difficult-to-Treat Hypertensive Patient. High Blood Press Cardiovasc Prev. 2020;27(2):109-17. 
11. Bhatt DL, Kandzari DE, O'Neill WW, et al. A controlled trial of renal denervation for resistant hypertension. New Engl J Med. 2014;370:1393-401.

12. Böhm M, Kario K, Kandzari DE, Mahfoud F, Weber MA, Schmieder R, Tsioufis K, Pocock S, Konstantinidis D, Choi JW. Efficacy of catheter-based renal denervation in the absence of antihypertensive medications (SPYRAL HTN-OFF MED Pivotal): a multicentre, randomised, sham-controlled trial. Lancet (London, England). 2020. https://doi.org/10.1016/S0140-6736(20)30554-7.
13. Rimoldi SF, Scherrer U, Messerli FH. Secondary arterial hypertension: when, who, and how to screen? Eur Heart J. 2014;35:1245-54.

14. Shay LA, Lafata JE. Where is the evidence? A systematic review of shared decision making and patient outcomes. Med Decis Making. 2015;35:114-31.

15. Schmieder RE, Hogerl K, Jung S, Bramlage P, Veelken R, Ott C. Patient preference for therapies in hypertension: a cross-sectional survey of German patients. Clin Res Cardiol. 2019;108:1331-422. 